\title{
GRUPOS EMPRESARIAIS NA EDUCAÇÃO BÁSICA PÚBLICA BRASILEIRA: LIMITES À EFETIVAÇÃO DO DIREITO À EDUCAÇÃO
}

\author{
Theresa Maria de Freitas Adriáo ${ }^{1}$ \\ Teise de Oliveira Guaranha Garcia ${ }^{2}$ \\ Raquel Fontes Borghi ${ }^{3}$ \\ Regiane Helena Bertagna ${ }^{3}$ \\ Gustavo Bottura Paiva ${ }^{4}$ \\ Salomấo Barros Ximenes ${ }^{5}$
}

\begin{abstract}
RESUMO: Este artigo analisa, com base em fontes primárias, fundamentalmente documentos oficiais e institucionais, e em entrevistas com gestores municipais, a atuação de cinco grupos empresariais em redes municipais de educação básica. Interessou-nos identificar as consequências da adoção por municípios brasileiros dos sistemas privados de ensino para a composição dos gastos das receitas vinculadas em educação e para a efetivação do direito à educaçáo. A pesquisa confirma trabalhos anteriores que indicam o deslocamento dos fundos públicos para o setor privado, até mesmo para corporaçóes transnacionais.
\end{abstract}

Palavras-chave: Privatização. Sistemas privados de ensino. Direito à educação.

\section{CORPORATE GROUPS IN THE BRAZILIAN PUBLIC BASIC EDUCATION: LIMITS ON THE REALIZATION OF THE RIGHT TO EDUCATION}

ABSTRACT: This paper analyzes, based on primary sources, mainly official and institutional documents, and on interviews with municipal managers, the performance of five business groups in municipal basic education systems. It is aimed to identify the outcomes of the adoption of private education systems by Brazilian municipalities for the composition of earmarked revenues spending for education and for the right to education. The research confirms previous studies that indicates the shift of public funds to the private sector, including transnational corporations.

Keywords: Privatization. Private education systems. Right to education.

\footnotetext{
${ }^{1}$ Universidade Estadual de Campinas, Faculdade de Educação, Departamento de Políticas, Administração e Sistemas Educacionais - Campinas (SP), Brasil. E-mail: theadriao@gmail.com ${ }^{2}$ Universidade de São Paulo, Faculdade de Filosofia, Ciências e Letras, Departamento de Educação, Informação e Comunicação - Ribeirão Preto (SP), Brasil. E-mail: teise@ffclrp.usp.br ${ }^{3}$ Universidade Estadual Paulista "Júlio de Mesquita Filho" (UNESP), Instituto de Biociências, Departamento de Educação - Rio Claro (SP), Brasil. E-mail: raborghi@gmail.com; regiane.bertagna@gmail.com ${ }^{4}$ ONG Ação Educativa. Programa Observatório da Educação - São Paulo (SP), Brasil.

E-mail: gustavo.paiva@acaoeducativa.org

${ }^{5}$ Universidade Federal do ABC (UFABC), Centro de Engenharia, Modelagem e Ciências Sociais Aplicadas (CECS) - São Bernardo do Campo (SP), Brasil. E-mail: salomao.ximenes@ufabc.edu.br DOI: 10.1590/ES0101-73302016157605
} 


\section{GROUPES D'ENTREPRISES DANS L'ENSEIGNEMENT DE BASE PUBLIC BRÉSILIEN: LIMITES À MISE EN OEUVRE DU DROIT À L'ÉDUCATION}

RESUMÉ: Cet article analyse, fondé sur des sources primaires, principalement sur des documents officiels et institutionnels ainsi que des entretiens avec des gestionnaires municipaux, la performance de cinq groupes entrepreneuriaux dans des réseaux municipaux de l'éducation de base. Nous avons porté notre intérêt sur l'identification des conséquences de l'adoption par les villes brésiliennes, des systèmes privés d'enseignement pour la composition des dépenses des recettes liées à l'éducation et pour la mise en oeuvre du droit à l'éducation. La recherche confirme les travaux antérieurs qui indiquent le transfert des fonds publics pour le secteur privé, même pour les corporations transnationales.

Mots-clés: Privatisation. Systèmes privés de l'enseignement. Droit à l'éducation.

\section{Introdução}

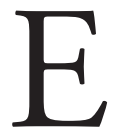

ste texto apresenta resultados de pesquisa ${ }^{1}$ que teve por objetivos caracterizar e analisar a adoção de sistemas privados de ensino por redes públicas municipais de educação básica no Brasil, considerando as consequências dessa opção de política para a efetivação do direito humano à educação.

Em 2013, segundo dados do Censo Escolar 2013 (BRASIL, 2014), 23.224.479 $(45,9 \%)$ das matrículas da educação básica estavam sob a responsabilidade dos municípios brasileiros. Levando em conta a desigualdade apresentada por essa oferta (BORGHI, 2007) e também a profundamente desigual repartição dos fundos públicos entre os entes federados no Brasil, esta investigação pensou ser relevante qualificar a análise sobre a adoção dos chamados sistemas privados de ensino (SPEs) vendidos aos municípios, pelos cinco maiores grupos empresariais do segmento educacional em atuação no ano de 2013, identificados com base em pesquisas anteriores. São eles: Pearson, Abril Educação, Santillana, Grupo Objetivo e Grupo Positivo.

Os SPEs consistem em uma cesta de produtos e serviços:

integrada por atividades tradicionalmente desenvolvidas pelas equipes pedagógicas dos órgãos da administração pública e das escolas: formação continuada de educadores, acompanhamento e supervisão das atividades docentes; investimento na produção e distribuiçãao de materiais didáticos aos alunos; processos de avaliação externa e interna, entre as principais encontradas (ADRIÃO et al., 2009, p. 806). 
Em um primeiro momento, realizou-se o mapeamento de municípios brasileiros que adotaram, em 2013, sistemas privados de ensino de uma das cinco empresas citadas anteriormente. Tal mapeamento aconteceu por meio de diferentes formas de coleta e com grandes dificuldades para acesso a informaçóes. Entre os 339 municípios identificados, selecionaram-se sete para detida caracterização e análise acerca da adoção de sistemas privados de ensino por redes públicas municipais, analisando seus impactos orçamentários e para o direito à educação.

A seleção dos casos em estudo decorreu dos seguintes critérios: ter adotado um dos sistemas privados de ensino vendidos pelos cinco maiores grupos empresariais da área; encontrar-se nas faixas mais altas $(0,7$ a 1,0$)$ ou nas mais baixas (0 a 0,599) do Índice de Desenvolvimento Humano Municipal $(\mathrm{IDHM})^{2}$; e ter gestores municipais que aceitassem conceder entrevista. Os sete municípios que atenderam a essas características serão aqui apresentados por números romanos seguidos dos estados de origem: I/SP, II/SP, III/SP, IV/SC, V/ SP, VI/AL, VII/BA.

Em cada município, fez-se entrevista com gestores educacionais com vistas a identificar: como se deu a decisão sobre a adoção do sistema de ensino privado para a rede municipal; o ano de início da adoção do sistema de ensino; os serviços contratados pelo município; os gastos municipais com a compra do sistema de ensino privado; a proporção desses gastos em relação aos gastos municipais com Manutenção e Desenvolvimento do Ensino $(\mathrm{MDE})^{3}$; a regulação jurídica da parceria; a utilização concomitante ou não de livros do Programa Nacional do Livro Didático (PNLD) ${ }^{4}$; as etapas da educação básica; e o número de alunos da rede municipal que usam o sistema contratado.

Com exceção dos municípios VI/AL e VII/BA, de baixo IDHM, os outros cinco pesquisados se encontravam nas faixas mais altas do índice. A opção pela seleçáo por meio do IDHM buscou tipificar os municípios nas duas extremidades da escala de desenvolvimento, uma vez que uma das hipóteses deste trabalho é que os fundos públicos de MDE, quando canalizados para grupos privados, representam uma estratégia de privatização da educação básica, que cria diferentes obstáculos à realização do direito humano à educação.

O direito humano à educaçáo, por sua vez, é tomado com base em sua concepção ampla, na forma como foi desenvolvida pelo Comitê de Direitos Econômicos, Sociais e Culturais da Organização das Naçóes Unidas (ONU) mediante as quatro características propostas por Tomasevski (2001), que foram incorporadas em 1999 à Recomendação Geral no 13 do referido comitê. São elas: disponibilidade, acessibilidade, aceitabilidade e adaptabilidade.

A disponibilidade determina a existência de oportunidades educacionais em número suficiente, enquanto a acessibilidade impóe que tais oportunidades 
não sejam meramente formais, mas que assegurem acessibilidade física, econômica e não discriminação no acesso à educação. A aceitabilidade está associada à garantia de uma educaçáo aceitável socialmente, ou seja, que respeite os direitos humanos e os propósitos públicos, como a cidadania, a redução das desigualdades e a sustentabilidade socioambiental. Já a adaptabilidade requer que se afiance a gestão democrática da educação, com a participação ativa de entes subnacionais, escolas e comunidades escolares, na produção das propostas político-pedagógicas, respeitados os direitos e deveres gerais.

A compreensão da relação entre privatização e direito humano à educação passa, com base nesse referencial, pela definição dos deveres do Estado quanto à efetivação das diferentes características do direito à educação, mesmo quando esta é ofertada pela iniciativa privada. Segundo o mesmo documento, os deveres do Estado no tocante à concretização de cada característica do direito podem ser classificados como deveres de respeitar, de proteger ou de realizar.

Para Ximenes (2014), considerando a realidade constitucional brasileira, o dever de respeitar e proteger o direito à educação contempla: o conjunto de liberdades educacionais, ou seja, a liberdade de ensino, quanto à criação e à escolha de escola privada; as liberdades no ensino, envolvendo a liberdade acadêmica dos professores e dos alunos; o pluralismo de ideias e de concepçóes pedagógicas; e os requisitos relativos à gestão democrática do ensino público, que limitam a atuação da administração central, abrindo espaço à participação na condução das escolas e da política educacional. Esses deveres estatais de respeito e proteção estâo diretamente conectados e são dependentes daqueles deveres que comumente caracterizam o direito educacional, ou seja, os deveres de provimento direto da educação escolar pelo Estado.

Portanto, segundo Ximenes (2014), há dever estatal de promover diretamente a educação de qualidade, aceitável, adaptável e não discriminatória nas instituições públicas e privadas. Ainda que as últimas sejam livres para constituir escolas, não o são quanto ao conteúdo e aos deveres educacionais. Por outro lado, o provimento de escolas públicas estatais não autoriza a administração central do Estado a geri-las de forma centralizada e/ou autoritária. Diferentemente das concepções puramente liberais, de um lado, ou de concepções totalitárias, de outro, o referencial normativo de direitos humanos não dá margem, liberdade absoluta na educação privada nem falta de liberdade na educação pública. Nesse referencial, em termos complementares, não resta dúvida que cabe ao Estado assegurar a realização do direito humano à educação em todas as instituiçóes, públicas e privadas, e no próprio sistema educacional.

Nossa análise, então, procurou identificar, com base no mapeamento e nos estudos de caso, os pontos em que a adoção de SPE pelos municípios colocam em risco o direito à educação assim compreendido. 


\section{Os cinco maiores grupos privados e o mercado educacional das redes públicas}

Como apontado, com base em pesquisas anteriores, selecionaram-se as cinco empresas privadas com maior presença no mercado educacional, via oferta de serviços e produtos educacionais para o setor público brasileiro. Tais investigações tiveram como campo empírico o estado de São Paulo, o qual concentra cerca de $30 \%$ das matrículas da educação básica.

No ano de referência, quatro das corporaçóes estudadas forneciam, entre seus produtos, sistemas educacionais privados destinados exclusivamente ao atendimento de redes públicas de ensino. São elas:

- Grupo Objetivo: Sistema Objetivo Municipal de Ensino (Some). A distribuição dos materiais é realizada pela editora Sol Soft;

- Pearson: sistema de ensino para a área pública oferecido via Núcleo de Apoio a Municípios e Estados (Name $)^{5}$ que conta com três produtos para escolas públicas, além do sistema Colégio Oswaldo Cruz (COC), para a rede privada;

- Grupo Positivo: Sistema de Ensino Aprende Brasil (Sabe), para a rede pública, e Sistema Positivo de Ensino, para as escolas privadas;

- Grupo Santillana: Sistema Uno Público de Ensino, oferecido para as escolas privadas, além de outros produtos.

A quinta empresa pesquisada, a Abril Educação (atualmente denominada Somos Educação), não mantinha um setor ou sistema específico para redes públicas, contudo comercializava para escolas públicas e privadas, além do Sistema Anglo de Ensino, objeto deste mapeamento, outros produtos ${ }^{6}$.

As corporaçôes, por sua vez, integram um cenário complexo de grandes e vultosas negociaçóes. Três grupos de capital aberto - Abril Educação, Pearson e Santillana - protagonizaram recentemente grandes negociaçóes em bolsa de valores, envolvendo a venda dos sistemas privados de ensino para redes públicas. Salienta-se que nesse mercado as matrículas públicas são tomadas como "ativos" das empresas (ADRIÁO et al. 2009; 2013). Esse aspecto merece especial atenção, uma vez que, para além das negociaçóes decorrentes da compra de produtos para atender às diferentes demandas das escolas públicas, processo identificado há mais de duas décadas no Brasil e também em outras partes do mundo (HILL, 2003; DALE, 1994), os sistemas privados de ensino inauguraram uma estratégia distinta quanto à presença das corporações na esfera pública, pois se trata da contabilização das matrículas como uma espécie de mercado futuro. 


\section{Os municípios pesquisados: revelações sobre os sistemas privados de ensino}

\section{Os municípios, suas estruturas de gestão e os sistemas privados}

Foram sete os municípios que compuseram o estudo - cinco deles com IDHM alto ou muito alto e dois com baixo IDHM. A proposta inicial era realizar os estudos qualitativos identificando dois municípios para cada um dos cinco grupos empresariais em análise — um com alto IDHM e outro com IDHM baixo ou muito baixo, totalizando dez municípios. No entanto, no universo averiguado, não foi identificado nenhum município com IDHM muito baixo que tivesse adotado, em 2013, um dos sistemas estudados. Também não foram encontrados municípios com IDHM baixo que tivessem adotado um sistema privado de ensino das empresas Grupo Objetivo, Abril Educação e Santillana. Dessa maneira, o Quadro 1 apresenta os municípios pesquisados.

\section{Quadro 1}

Municípios que compuseram o estudo qualitativo, por grupo empresarial/ sistemas privados de ensino e índice de desenvolvimento humano municipal.

\begin{tabular}{|l|c|c|}
\hline $\begin{array}{l}\text { Empresas e sistema } \\
\text { privado de ensino }\end{array}$ & $\begin{array}{c}\text { Municípios com } \\
\text { alto IDHM }\end{array}$ & $\begin{array}{c}\text { Municípios com } \\
\text { baixo IDHM }\end{array}$ \\
\hline Santillana/Uno Público & Município I/SP* & - \\
\hline Abril Educação/Anglo & Município II/SP & - \\
\hline Pearson/Name & Município III/SP & Município VI/AL \\
\hline Positivo/Sabe & Município IV/SC & Município VII/BA \\
\hline Objetivo/Some & Município V/SP & - \\
\hline
\end{tabular}

Fonte: ADRIÄO et al., 2015.

IDHM: indice de desenvolvimento humano municipal.

*Apenas o município I/SP refere-se ao ano de 2012. Segundo depoimento, a partir de 2013 o referido município trocou de empresa fornecedora do sistema, para diminuir os gastos com esse tipo de despesa.

As informaçóes sobre a capacidade administrativa, fornecidas pelos municípios, estão indicadas no Quadro 2, pelo qual se percebe que o município III/ SP é o único entre os pesquisados que não possui seu próprio sistema municipal de educação, estando atrelado ao sistema estadual, ainda que possua os demais conselhos gestores. Os municípios I/SP e II/SP têm seus próprios sistemas municipais, planos municipais de educação e colegiados diretores nas unidades escolares, além de apresentarem alto índice de desenvolvimento. Ou seja, formalmente, teriam condiçôes para desenvolver e implantar suas próprias políticas educacionais.

Também foi realizado um levantamento acerca da participação dos municípios no PNLD. Com exceção dos municípios I/SP e II/SP, os quais optaram por receber apenas obras complementares, todos os demais se mantiveram vinculados ao programa. Além 


\section{Quadro 2}

Administração da rede de escolas municipais por município selecionado (presença de sistema próprio, plano municipal e conselhos).

\begin{tabular}{|c|c|c|c|c|c|c|c|}
\hline & 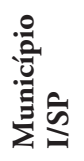 & 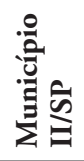 & 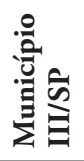 & 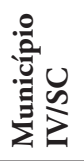 & 递 & 总总 & 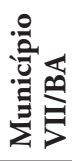 \\
\hline Sistema municipal de educação & $\operatorname{sim}$ & $\operatorname{sim}$ & não & $\operatorname{sim}$ & $\operatorname{sim}$ & $\operatorname{sim}$ & $\operatorname{sim}$ \\
\hline Plano municipal de educação & $\operatorname{sim}$ & $\operatorname{sim}$ & não & $\operatorname{sim}$ & não & $\operatorname{sim}$ & não \\
\hline Conselho Municipal de Educação & $\operatorname{sim}$ & $\operatorname{sim}$ & $\operatorname{sim}$ & $\operatorname{sim}$ & $\operatorname{sim}$ & $\operatorname{sim}$ & $\operatorname{sim}$ \\
\hline Conselho do Fundeb & $\operatorname{sim}$ & $\operatorname{sim}$ & $\operatorname{sim}$ & $\operatorname{sim}$ & $\operatorname{sim}$ & $\operatorname{sim}$ & $\operatorname{sim}$ \\
\hline Conselhos escolares & $\operatorname{sim}$ & $\operatorname{sim}$ & $\operatorname{sim}$ & não & $\operatorname{sim}$ & não & $\operatorname{sim}$ \\
\hline
\end{tabular}

Fonte: ADRIÃO et al., 2015.

disso, V/SP, VI/AL e VII/BA receberam tais obras em proporção bastante elevada, considerando-se o gasto efetuado pelos municípios para a compra dos sistemas privados de ensino.

Em relaçáo ao processo de tomada de decisão no que diz respeito à adoção dos SPEs e dos procedimentos para a seleção do sistema, o Quadro 3 sintetiza informaçôes obtidas por meio das entrevistas.

Tendo em vista os depoimentos sintetizados no Quadro 3, considerou-se necessário, para efeito de análise da presença dos SPEs nas redes públicas, diferenciar dois momentos que compóem o processo de decisão sobre essa política. O primeiro momento é a própria decisão sobre adotar ou não um sistema privado de ensino. Já o segundo se refere à decisão concernente a que sistema adotar entre aqueles ofertados pelo mercado educacional privado. Há poucas menções explícitas a essa primeira decisão nas entrevistas, ainda que se deva presumir que esse tipo de opção política é da esfera natural de atribuição do secretário de Educaçáo ou do prefeito. No município I/SP, por exemplo, o entrevistado reconheceu expressamente que coube ao prefeito local decidir pela adoção do sistema, sem participação dos órgáos colegiados do campo educacional ou das escolas. Uma vez tomada essa decisão, conforme o entrevistado, vem sendo realizado anualmente processo licitatório para a compra do sistema privado, combinando-se uma avaliação do município quanto aos materiais disponíveis e aos preços ofertados. A pouca variação entre os sistemas contratados, entretanto, demonstra que o fator continuidade tem grande peso na escolha, até por razóes de ordem pedagógica.

Levando em conta os depoimentos, nota-se ainda que a percepçáo sobre a qualidade dos sistemas privados é autorreferenciada, apoiada em fortes estratégias publicitárias e tem como base o desempenho de escolas privadas ligadas aos mesmos grupos empresariais que em nada se parecem com as escolas públicas municipais, já que aquelas estáo voltadas à população de maior renda e têm como razão de existência a segmentação socioeconômica que produzem. Mesmo que as empresas adotem diferentes estratégias, em geral foram identificados grandes investimentos 


\section{Quadro 3}

Informaçóes sobre processos de seleção e implantação dos sistemas privados de ensino pelos municípios.

\begin{tabular}{|c|c|c|c|}
\hline Municípios & $\begin{array}{l}\text { Procedimento para } \\
\text { seleçáo do SPE }\end{array}$ & $\begin{array}{c}\text { Tomada de decisáo sobre a } \\
\text { adoçáo do SPE }\end{array}$ & $\begin{array}{l}\text { Início da } \\
\text { implantação } \\
\text { do SPE }\end{array}$ \\
\hline $\begin{array}{l}\text { Município I/SP*: } \\
\text { Santillana/Sistema } \\
\text { Uno Público }\end{array}$ & Licitação & Prefeito & 2005 \\
\hline $\begin{array}{l}\text { Município II/SP: } \\
\text { Abril Educação/Anglo }\end{array}$ & $\begin{array}{c}\text { Presença de escola } \\
\text { privada Anglo no } \\
\text { município, com } \\
\text { licitação (contrato de } \\
\text { cinco anos renováveis) }\end{array}$ & Secretaria de Educação & 2005 \\
\hline $\begin{array}{l}\text { Município III/SP: } \\
\text { Pearson/Name }\end{array}$ & $\begin{array}{l}\text { Licitação (contrato de } \\
\text { cinco anos, renovável } \\
\text { anualmente) }\end{array}$ & $\begin{array}{l}\text { Proposição do prefeito e } \\
\text { posterior análise de comissão } \\
\text { por ele criada para a escolha } \\
\text { do material de três empresas: } \\
\text { Objetivo, Positivo e Pearson }\end{array}$ & 2009 \\
\hline $\begin{array}{l}\text { Município IV/SC: } \\
\text { Positivo/Sabe }\end{array}$ & $\begin{array}{c}\text { Foram analisados } \\
\text { diferentes SPEs (Anglo, } \\
\text { Grupo Opet, Objetivo } \\
\text { e Pearson). } \\
\text { Optou-se pelo SPE } \\
\text { do Positivo, o que se } \\
\text { justifica pela presença } \\
\text { do grupo na região }\end{array}$ & $\begin{array}{l}\text { Secretaria de Educação e } \\
\text { diretores de escolas, com } \\
\text { validação do Conselho } \\
\text { Municipal de Educaçáo }\end{array}$ & $\begin{array}{l}\text { A data } \\
\text { informada pelo } \\
\text { respondente foi } \\
\text { anterior a } 2012\end{array}$ \\
\hline $\begin{array}{l}\text { Município V/SP: } \\
\text { Grupo Objetivo/ } \\
\text { Some }\end{array}$ & $\begin{array}{l}\text { Licitação pública, após } \\
\text { análise dos supervisores } \\
\text { de alguns SPEs }\end{array}$ & Gestão municipal & 2008 \\
\hline $\begin{array}{l}\text { Município VI/AL: } \\
\text { Pearson/Name }\end{array}$ & $\begin{array}{c}\text { Houve análise dos SPEs } \\
\text { de várias empresas } \\
\text { (Alfabeto, Pearson e } \\
\text { Positivo) e optou-se } \\
\text { pela Pearson }\end{array}$ & $\begin{array}{l}\text { Técnicos da Secretaria de } \\
\text { Educação e coordenadores } \\
\text { pedagógicos das escolas, } \\
\text { com aprovação do Conselho } \\
\text { Municipal de Educação }\end{array}$ & $2010^{* *}$ \\
\hline $\begin{array}{l}\text { Município VII/BA: } \\
\text { Grupo Positivo/Sabe }\end{array}$ & $\begin{array}{l}\text { Decidido pela gestão } \\
\text { anterior }\end{array}$ & $\begin{array}{l}\text { Respondente não soube } \\
\text { informar }\end{array}$ & 2010 \\
\hline
\end{tabular}

SPE: sistemas privados de ensino;

*Antes do SPE Sistema Uno Público, o município adotou o SPE da Pearson;

** SPE teve o nome alterado de COC para Name após a aquisição de parte dos ativos do grupo pela Pearson; Fonte: ADRIÃO et al., 2015.

na promoção dessa visão que busca relacionar melhoria da qualidade da educação e adoção dos sistemas padronizados de ensino, como já apontaram Bertagna e Borghi (2011). Essa publicidade, em alguns casos, está direcionada aos gestores das escolas públicas, até mesmo com a distribuição direta das revistas que as veiculam aos prefeitos e secretários de Educação (Fonte: ADRIÃO et al., 2015). 
Esse fator evidencia-se no caso de II/SP, no qual o material Anglo foi adotado em razão da presença, no município, de uma escola privada com o mesmo sistema de ensino. Ele também aparece na justificativa do gestor para a adoção do sistema Positivo em IV/SC, já que este seria uma "marca forte" no estado.

\section{As despesas municipais com a compra do sistema privado de ensino}

A Constituição Federal (BRASIL, 1988) e a Lei de Diretrizes e Bases da Educação Nacional (LDB) (BRASIL, 1996a) definem que os estados, os municípios e o Distrito Federal devem aplicar, no mínimo, 25\% da receita resultante de impostos e transferências para a MDE. Conforme Bassi (2011, p. 119), "a vinculação, como ficou conhecido esse dispositivo, gera, de longe, o montante de recursos mais significativo para o financiamento da educação municipal".

A LDB estabelece também o que é considerado despesa com MDE, entre as quais se destacam: remuneração e aperfeiçoamento dos profissionais da educação; aquisição, manutençáo, construção e conservação de instalaçôes e equipamentos necessários ao ensino; uso e manutenção de bens e serviços vinculados ao ensino; estudos e pesquisas que visam ao aprimoramento da qualidade e à expansão do ensino; realização de atividades-meio essenciais ao funcionamento dos sistemas de ensino; concessão de bolsas de estudo a alunos de escolas públicas e privadas; manutenção de programas de transporte escolar; e aquisiçẫo de material didático escolar.

Nesse sentido, tendo em vista que a aquisição de material didático escolar é tida como um gasto em MDE, foram objetos do estudo de caso identificar e analisar o impacto da compra dos sistemas privados de ensino nas despesas municipais.

O valor aproximado aplicado pelos municípios na compra do sistema privado de ensino foi calculado com base na divisão entre o valor total gasto com o SPE e o número de alunos atendidos nas etapas nas quais o serviço foi adotado.

A Tabela 1 mostra que a menor quantia aproximada gasta por aluno/ano para a compra de sistemas privados de ensino foi de $\mathrm{R} \$ 143,04$, no município V/ SP, com a empresa Objetivo. Já o maior valor foi gasto pelo município IV/SC, para a compra do sistema vendido pelo Grupo Positivo. Entretanto, o destaque cabe ao gasto/aluno efetuado pelo município VII/BA, de baixo IDHM e que, em 2013, para cumprir o gasto mínimo definido pelo Fundo de Manutenção e Desenvolvimento da Educaçâo Básica e de Valorização dos Profissionais da Educação (Fundeb), recebeu complementaçẫo da União da ordem de R $\$ 254.873,53$ (BRASIL, 2013).

Além disso, confirmou-se condição identificada em outras pesquisas (ADRIÂO et al, 2009 e 2013), segundo as quais uma mesma empresa pratica diferenciação nos custos de seu SPE em função dos municípios clientes, como ocorre com o SPE do grupo Positivo, adquirido pelo custo por aluno de $\mathrm{R} \$ 279,82$ por VII/BA e de R \$ 394,98 por IV/SC. 


\section{Tabela 1}

Valor nominal aproximado do sistema privado de ensino por aluno/ano nas etapas atendidas (2013).

\begin{tabular}{|c|c|c|c|c|}
\hline Municípios/SPE & $\begin{array}{c}\text { Gasto total } \\
\text { SPE (R\$) }\end{array}$ & $\begin{array}{c}\text { Etapas } \\
\text { atendidas }\end{array}$ & No de alunos & $\begin{array}{c}\text { Valor aluno } \\
\text { ano }(\mathrm{R} \$)\end{array}$ \\
\hline \multicolumn{5}{|c|}{ Municípios com alto IDHM } \\
\hline I/SP (Uno Público)* & $739.859,71$ & EI e EF & 2.323 & 318,49 \\
\hline II/SP (Anglo) & $2.219 .687,51$ & EI e EF & 6.888 & 322,25 \\
\hline III/SP (Name) & $632.771,04$ & $\mathrm{EI}$ e EF & 3.964 & 159,62 \\
\hline IV/SC (Sabe) & $320.332,18^{* *}$ & $\mathrm{EF}$ & 811 & 394,98 \\
\hline V/SP (Some) & $4.092 .240,99$ & EI, EF e EM & 28.608 & 143,04 \\
\hline \multicolumn{5}{|c|}{ Municípios com baixo IDHM } \\
\hline VI/AL (Name) $)^{* * *}$ & - & - & - & \\
\hline VII/BA (Sabe) $)^{* * * *}$ & $516.558,62$ & $* * * * *$ & 1.787 & 279,82 \\
\hline
\end{tabular}

Fonte: Tribunal de Contas do Estado (SP, SC, AL e BA) e Censo Escolar 2013 (BRASIL, 2014). EI: educação infantil; EF: ensino fundamental; EM: ensino médio; SPE: sistemas privados de ensino; IDHM: Indice de desenvolvimento humano municipal;

*Dados são referentes a 2012;

**Valores gastos com o sistema privado de ensino de janeiro a junho de 2013;

***Não há informação no Tribunal de Contas do Estado sobre as etapas atendidas. Adotou-se como metodologia a divisão do gasto com o SPE pelo total de matrículas municipais; ****Não foram encontradas informaçóes relativas ao município de VI/BA; ****Informaçâo fornecida na entrevista.

Chama a atenção o uso desse tipo de estratégia e política educativa para a educação infantil, tendência que estudos reconheceram ter início em 1998 e que se aprofundou a partir dos anos 2000, inclusive para as creches (ADRIÂO et al., 2013).

A proporção entre o gasto municipal anual com SPE e os gastos totais dos municípios na função educação, para o que se consultaram informaçôes no Sistema de Informações sobre Orçamentos Públicos em Educaçãoo (Siope), encontra-se indicada na Tabela 2.

Os municípios pesquisados destinaram entre 2 e $6 \%$ dos gastos totais na função educação ao pagamento dos SPEs. Se a proporção for considerada com base na aproximação com o gasto aluno/ano efetuado pelos municípios em 2013, os percentuais são muito significativos, conforme exposto na Tabela 3 .

Mais uma vez, destaca-se o fato de os valores desembolsados pelos municípios não dependerem das condiçôes socioeconômicas expressas no IDHM, uma vez que o maior e o menor gasto com os SPEs foram executados por municípios de alto IDHM para a aquisiçáo de distintos sistemas privados de ensino: Name e Anglo.

Para identificar os perfis municipais e sua relação com a atuação dos grupos empresariais, o Quadro 4 informa o total de alunos atendidos por essa política e o tipo de serviço e/ou produto adquirido pelos municípios. 


\section{Tabela 2}

Gastos com o sistema privado de ensino e gastos totais dos municípios na função educação (2013) (valores nominais).

\begin{tabular}{l|c|c|c}
\hline Municípios/SPE & $\begin{array}{c}\text { Gasto total } \\
\text { SPE (R\$) }\end{array}$ & $\begin{array}{c}\text { Gasto total funçáo } \\
\text { educaçáo (R\$) }\end{array}$ & $\begin{array}{c}\text { Participaçáo } \\
\text { relativa do SPE (\%) }\end{array}$ \\
\hline \multicolumn{4}{l|}{ Municípios com alto IDHM } \\
\hline I/SP (Uno Público) & $739.859,71$ & $16.147 .464,09$ & 4,58 \\
\hline II/SP (Anglo) & $2.219 .687,51$ & $38.984 .620,49$ & 5,69 \\
\hline III/SP (Name) & $632.771,04$ & $29.865 .664,34$ & 2,11 \\
\hline IV/SC (Sabe) & $320.332,18^{*}$ & $8.539 .180,03$ & 3,75 \\
\hline V/SP (Some) & $4.092 .240,99$ & $199.105 .166,43$ & 2,05 \\
\hline Municípios com baixo IDHM & & & \\
\hline VI/AL (Name)** & - & $10.021 .450,66$ & - \\
\hline VII/BA (Sabe) & $516.558,62$ & $13.926 .865,96$ & 3,7 \\
\hline
\end{tabular}

Fonte: adaptado de Tribunal de Contas do Estado (SP, SC, AL e BA) e Siope.

SPE: sistemas privados de ensino; IDHM: Índice de desenvolvimento humano municipal;

${ }^{*}$ Gasto de janeiro a junho de 2013;

**Não foram encontrados dados acerca dos gastos com a aquisição do SPE pelo município VI/AL.

\section{Tabela 3}

Gasto com sistema privado de ensino por aluno ao ano* em relação aos gastos totais por aluno ao ano nas etapas atendidas (2013).

\begin{tabular}{|c|c|c|c|}
\hline Municípios/sistema privado & $\begin{array}{l}\text { Gasto total por } \\
\text { aluno/ano }(\mathrm{R} \$)\end{array}$ & $\begin{array}{c}\text { Gasto total por } \\
\text { aluno/ano para } \\
\text { compra do SPE (R\$) }\end{array}$ & $\begin{array}{c}\text { Participaçáo } \\
\text { relativa do SPE } \\
(\%) \text { nos gastos } \\
\text { com educaçáo }\end{array}$ \\
\hline \multicolumn{4}{|l|}{ Municípios com alto IDHM } \\
\hline I/SP (Uno Público) & $6.124,37$ & 318,49 & 5,20 \\
\hline II/SP (Anglo) & $4.961,00$ & 322,25 & 6,49 \\
\hline III/SP (Name) & $6.899,05$ & 159,62 & 2,31 \\
\hline IV/SC (Sabe) & $5.616,12$ & 394,98 & 7,03 \\
\hline V/SP (Some) & $5.440,96$ & 143,04 & 2,62 \\
\hline \multicolumn{4}{|l|}{ Municípios com baixo IDHM } \\
\hline VI/AL (Name)** & - & - & - \\
\hline VII/BA (Sabe) & $6.651,38$ & 279,82 & 4,20 \\
\hline
\end{tabular}

Fonte: Tribunal de Contas do Estado (SP, SC, AL e BA) e Siope.

SPE: sistemas privados de ensino; IDHM: Índice de desenvolvimento humano municipal;

${ }^{*} O$ gasto por aluno ao ano nas etapas atendidas foi calculado com base em dados do Siope (especificamente o demonstrativo da função educação). Desse modo, se o município adotou um sistema privado para o ensino fundamental e para a educação infantil, somaram-se as despesas realizadas nessas duas etapas da educação básica;

**Não foram encontrados dados acerca dos gastos com o SPE para o município VI/AL. 


\section{Quadro 4}

Relação entre custo aproximado do sistema privado de ensino por aluno, alunos atendidos, etapa atendida e produtos e serviços contratados (2013).

\begin{tabular}{|c|c|c|c|c|c|}
\hline $\begin{array}{l}\text { Município/ } \\
\text { IDHM }\end{array}$ & $\begin{array}{c}\text { Custo } \\
\text { aluno/ } \\
\text { ano }(R \$)\end{array}$ & Empresa & Alunos & $\begin{array}{c}\text { Etapa } \\
\text { atendida }\end{array}$ & Itens que integram cada SPE \\
\hline $\begin{array}{l}\text { I/SP } \\
\text { IDHM alto }\end{array}$ & 318,49 & $\begin{array}{l}\text { Santillana/ } \\
\text { Uno } \\
\text { Público }\end{array}$ & 2.323 & EI e EF & $\begin{array}{l}\text { Apostilas para alunos e docentes, } \\
\text { duas atividades anuais de formação } \\
\text { para docentes, material especíico } \\
\text { para alunos com necessidades } \\
\text { especiais tipo baixa visão }\end{array}$ \\
\hline $\begin{array}{l}\text { II/SP } \\
\text { IDHM alto }\end{array}$ & 322,25 & $\begin{array}{l}\text { Abril } \\
\text { Educação/ } \\
\text { Anglo }\end{array}$ & 6.888 & EI e EF & $\begin{array}{l}\text { Apostilas para alunos e docentes, } \\
\text { oferta de videoconferências e } \\
\text { conferência presencial, assistência } \\
\text { pedagógica (uma assistente } \\
\text { pedagógica visita toda semana as } \\
\text { escolas), material com CD, revista, } \\
\text { estojo, lápis e outros materiais }\end{array}$ \\
\hline $\begin{array}{l}\text { III/SP } \\
\text { IDHM alto }\end{array}$ & 159,62 & $\begin{array}{l}\text { Pearson/ } \\
\text { Name }\end{array}$ & 3.964 & EI e EF & $\begin{array}{c}\text { Material apostilado para alunos e } \\
\text { docentes, acompanhamento bimestral } \\
\text { (com uma equipe nas escolas), acesso a } \\
\text { Tele Sala, no Portal Name, avaliaçóes/ } \\
\text { simulados, caderno de recuperação } \\
\text { aos alunos (os professores informam } \\
\text { quantos são necessários e é encaminhada } \\
\text { para as escolas a quantidade) }\end{array}$ \\
\hline $\begin{array}{l}\text { IV/SC } \\
\text { IDHM alto }\end{array}$ & 394,98 & $\begin{array}{l}\text { Positivo/ } \\
\text { Sabe }\end{array}$ & 811 & $\mathrm{EF}$ & $\begin{array}{l}\text { Apostilas para alunos e docentes, } \\
\text { acesso ao site para orientaçóes e } \\
\text { testes/simulados para preparação para } \\
\text { a Prova Brasil }\end{array}$ \\
\hline $\begin{array}{l}\text { V/SP } \\
\text { IDHM alto }\end{array}$ & 143,04 & $\begin{array}{c}\text { Objetivo/ } \\
\text { Some }\end{array}$ & 28.608 & $\begin{array}{c}\text { EI, EF e } \\
\text { EM }\end{array}$ & $\begin{array}{l}\text { Apostila para alunos e docentes, } \\
\text { formação para os professores com } \\
\text { capacitadores do SPE e acesso ao site }\end{array}$ \\
\hline $\begin{array}{l}\text { VI/AL } \\
\text { IDHM } \\
\text { baixo }\end{array}$ & - & $\begin{array}{l}\text { Pearson/ } \\
\text { Name }\end{array}$ & - & - & $\begin{array}{l}\text { Apostila para alunos e docentes, } \\
\text { formaçáo de professores, } \\
\text { acompanhamento pedagógico aos } \\
\text { professores e acompanhamento do } \\
\text { desenvolvimento das crianças (também } \\
\text { entendido como avaliaçáa), visitas às } \\
\text { aulas dos professores na escola, palestras } \\
\text { para os pais, acesso ao site, convênio } \\
\text { com a prefeitura, para graduaçáo e } \\
\text { especializaçáo dos professores }\end{array}$ \\
\hline $\begin{array}{l}\text { VII/BA } \\
\text { IDHM } \\
\text { baixo }\end{array}$ & 279,82 & $\begin{array}{l}\text { Positivo/ } \\
\text { Sabe }\end{array}$ & 1.787 & EI e EF & $\begin{array}{l}\text { Apostilas para alunos e docentes, } \\
\text { formaçáo de professores e acesso ao } \\
\text { site por meio de uma senha de acesso } \\
\text { (Portal Aprende Brasil) }\end{array}$ \\
\hline
\end{tabular}

EI: educação infantil; EF: ensino fundamental; EM: ensino médio; -: não há informaçōes disponiveis nas fontes consultadas; SPE: sistemas privados de ensino; IDHM: Índice de desenvolvimento humano municipal. 
Da análise do Quadro 4, ressalta-se que o município que teve o maior gasto/aluno com o SPE possui um pequeno número de alunos, entretanto tem um IDHM alto. No outro extremo, o município V/SP, que pagou o menor valor por aluno para aquisição do SPE, fê-lo para um total de 28.608 alunos matriculados, ao que parece sugerindo uma economia de escala na compra desses serviços.

Não há necessariamente relação direta entre custo/aluno e os itens que integram os serviços comprados em cada município. Se é verdade que o sistema de maior custo inclui pacote de avaliação e o de menor custo não, também foi verificado que no segundo mais caro estão incluídos outros materiais escolares, enquanto no terceiro mais caro a oferta está limitada ao pacote básico do SPE.

\section{Afirmando críticas e desafiando práticas: os limites à efetivação do direito à educação}

Analisemos de início a relação entre a adoção dos SPEs e a disponibilidade e acessibilidade da educação.

As evidências apresentadas explicitam a precariedade de muitas das administraçóes locais, o que tem gerado um promissor mercado para assessorias privadas nos campos pedagógicos e de gestão, em detrimento dos mecanismos de participaçáo democrática e do fortalecimento de atores comprometidos com a estruturação de sistemas públicos de educação, por intermédio do desenvolvimento de capacidades nas próprias escolas e municípios (ADRIÁO et al., 2009; 2013). O governo federal fornece gratuitamente às redes municipais e estaduais material didático e paradidático para os ensinos fundamental e médio nas modalidades regular e Educação de Jovens e Adultos (EJA), por meio do PNLD. Somente em 2014, foi gasto mais de R $\$ 1,1$ bilhão (BRASIL, 2013) na compra de materiais didáticos para distribuir aos municípios, que, ainda assim, no caso daqueles que adotam os SPEs, deixaram de adotar os livros em sua rede para dispender recursos próprios na aquisição de tais sistemas. Esse fato tanto pode caracterizar a duplicação de gastos para o mesmo quesito - livros didáticos (ADRIÃO et al., 2009) - como, para aqueles entes federados que abrem mão formalmente do recebimento do livro do PNLD, a perda voluntária de recursos que seriam repassados pelo governo federal.

Como vimos, a compra de SPEs pelas redes municipais públicas, assim como o PNLD e demais iniciativas de "aquisição de material didático-escolar" (BRASIL, 1996a), pode ser contabilizada nas despesas com MDE. Isso significa que esse repasse direto de recursos públicos ao setor privado não sofre as limitaçôes impostas pelo artigo 213 da Constituição para o repasse estatal ao setor privado (BRASIL, 1988). 
Portanto, a crescente aplicação de recursos públicos na compra de SPEs associada aos altos lucros envolvidos em tais negociações e à perda de um recurso oferecido gratuitamente pelo governo federal reduz de maneira substancial a capacidade dos municípios de disponibilizar novas vagas no sistema público, por conta da redução dos recursos públicos disponíveis para a criação de oportunidades, sobretudo nas etapas não obrigatórias e naquelas em que é baixa a cobertura. Isso ocorre com prejuízo para as populaçōes mais pobres, crianças com idade de frequência à creche, jovens e adultos com baixa escolaridade e estudantes com deficiência ou com necessidades educativas especiais, ou seja, públicos normalmente excluídos da creche ou da escola, sob o argumento de ausência de recursos para a generalização do atendimento para além das etapas ou modalidades obrigatórias.

Por isso, alguns dos principais achados desta pesquisa são os dados relativos ao custo da adoção dos SPEs pelos municípios. Vimos na Tabela 1 que os valores gastos com material didático, por aluno/ano, variam significativamente entre os entes averiguados, de $\mathrm{R} \$ 143,04$ no município V/SP a $\mathrm{R} \$ 394,98$ no município IV/SC. Em termos percentuais, na Tabela 3 os gastos por aluno/ano com SPE variaram entre 2,31\% no município III/SP e 7,03\% no município IV/ SC. No município com baixo IDHM, VII/BA, essa despesa representou 4,20\% do gasto por aluno/ano.

O valor gasto com os sistemas em proporção ao aplicado, em cada município, na função educação reforça a percepção sobre a importância dessa despesa no orçamento municipal para o setor. A Tabela 2 demonstrou-nos que essa participação pode chegar a 5,69\% dessas despesas, como no caso do município II/SP, tendo como percentual mínimo 2,05\%, no município V/SP. Levando em conta que a participação das despesas correntes com pessoal docente e não docente representa a maior parte das despesas fixas com educação nos municípios, vemos que, ainda que minoritárias em relação ao gasto total, as despesas com SPE consomem uma parcela relativamente grande dos recursos de livre alocação, que poderiam ser aplicados em investimentos em infraestrutura ou em outros programas de fortalecimento da própria rede pública.

Estabelecemos como hipótese a ser verificada em estudos futuros que o percentual aplicado em compra de SPEs é equiparável, em alguns municípios, às despesas com investimentos na construção de unidades de educação infantil ou de reforma e qualificação das escolas existentes. Além disso, como as empresas educacionais influenciam bastante os rumos da própria política educacional, também não seria descabida a hipótese de que tal influência sobre o orçamento público está chegando fortemente nos gestores municipais, que deixam de investir na ampliação de sua capacidade de atendimento enquanto repassam recursos para a formação de lucro em tais empresas.

O repasse direto de recursos para a iniciativa privada por meio da compra de SPEs, até mesmo com a possibilidade de contabilização desses dispêndios 
em MDE, nesse contexto, incentiva a privatização, enfraquece a capacidade dos municípios de implementar diretamente o ensino naquelas etapas e modalidades em que há carência e tende a diminuir a infraestrutura, equipes técnicas e de gestão para a oferta de uma educação pública de qualidade, já que esta passa a ser, em parte, contratada externamente.

Ainda que se reconheça que uma parte do gasto é revertido em serviços, assessorias e materiais didático-pedagógicos, os SPEs têm como principal propósito carrear recursos públicos escassos para o lucro dos grupos empresariais. Tem-se, assim, um efeito negativo no objetivo de reduzir desigualdades sociais e educacionais.

O SPE não impediu, em geral, os municípios de solicitarem livros do PNLD. Aspecto positivo, pois se pode supor que as atividades didáticas não se reduziram apenas ao que está prescrito nas apostilas. Por outro lado, chama a atenção, mesmo do Ministério Público (MIZUKI, 2013), o fato de os governos gastarem duplicadamente recursos para o mesmo fim, já que os materiais didáticos dos sistemas privados veiculam conteúdos comumente presentes nos livros didáticos distribuídos pelo PNLD, conforme já identificado para outros contextos (ADRIÃO et al., 2009).

Quanto às tensões que a adoção de SPE produzem na realização da aceitabilidade e da adaptabilidade da educação, salientamos que a adoção dos SPEs nos municípios tende a limitar o debate sobre qualidade do ensino e a suplantar os espaços de deliberação democrática e de participação na gestão educacional.

Uma vez que os SPEs não passam por um processo de controle de qualidade por órgãos governamentais, como ocorre com os materiais do PNLD, não existe um sistema público de controle sobre a aceitabilidade (qualidade) dos materiais ou sua adequação às diretrizes curriculares. Na melhor das hipóteses, essa avaliação fica a cargo dos próprios municípios contratantes. Entretanto, os depoimentos mostram que esse procedimento pode ser posterior à decisão pela compra do SPE. Em alguns casos, reconheceu-se que, além de não haver um processo de análise da qualidade do material ofertado nem da adequação de sua proposta específica às demandas locais, a decisão quanto à adoção do SPE não passou pelos órgáos educacionais. Dos sete municípios analisados, em apenas dois deles os gestores afirmaram ter consultado as equipes pedagógicas das escolas e o Conselho Municipal de Educação para a escolha do SPE, o que ameaça a adaptabilidade e a aceitabilidade, exigências do direito à educação.

Ademais, diferentemente do PNLD, a compra dos pacotes pelos municípios não preserva a autonomia de professores nem de escolas na escolha dos materiais e das metodologias ofertadas. Há, portanto, perda em termos de adaptabilidade associada a retrocessos quanto à participação e à transparência pública. Como reflexo da característica central desses sistemas, sua adoção tende a violar os deveres estatais referentes ao reconhecimento da diversidade cultural e pedagógi- 
ca, que deveria ser respeitada, protegida e promovida pelo Estado. Como se pode depreender do conjunto de serviços ofertados, a adoção dos sistemas privados padronizados de ensino nas escolas públicas diminui drasticamente o espaço de adaptação curricular, bem como a autonomia pedagógica de escolas e professores, uma vez que as aulas, atividades e conteúdos passam a ser estandardizados e controlados com base nesse referencial.

Também é esse processo de padronização que passa a fundamentar as agendas de formação continuada que são contratadas pelos municípios a essas empresas. Os sistemas privados nas escolas públicas, com isso, tendem a submeter escolas, professores e estudantes à homogeneização e ao enfraquecimento de suas capacidades enquanto sujeitos ativos e criadores na realização do direito à educação. Nesse sentido, opóem-se à gestão democrática da educação e, mais grave que isso, promovem a dependência das redes públicas aos serviços privados, já que não estimulam o desenvolvimento de capacidades locais para a produção de propostas pedagógicas, formaçóes e avaliaçóes.

Por fim, para grupos historicamente marginalizados em seu direito à educação, a falta de transparência, de participação e de controle estatal sobre os SPEs coloca em dúvida sua capacidade de promoção da inclusão e do reconhecimento de estudantes com deficiência ou necessidades especiais, do campo, de comunidades indígenas e quilombolas e demais populações tradicionais.

\section{Considerações finais}

Esperava-se que a crescente participação do Estado na oferta de educação obrigatória e não obrigatória, ocorrida nas últimas décadas, viesse a reduzir o espaço do mercado na educação. No entanto, como identificamos neste trabalho, grupos empresariais e conglomerados econômicos têm buscado outras formas de lucrar com a educação que não exclusivamente com a oferta direta do ensino (matrículas em escolas privadas), colocando em risco os paradigmas de direitos humanos educacionais, que são substituídos pela lógica de mercado baseada no custo $\times$ benefício e na visão dos estudantes como mercadorias commodities. Essa perspectiva, que associa diretamente as debilidades do sistema público educacional brasileiro às oportunidades de negócio, é explicitamente expressa por alguns dos grupos empresariais (Fonte: ADRIÃO et al., 2015). A adoção dos SPEs - e não outros tipos de investimentos estatais - é apontada, entre outras vantagens, como a "solução eficiente para oferta de qualidade em um mercado com poucos professores bem formados e raros professores com dedicação exclusiva” (ABRIL EDUCAÇÃO, 2014).

A venda de SPEs para as redes públicas municipais constitui, portanto, uma importante vertente de privatização da educação no Brasil, com o desenvol- 
vimento de um mercado competitivo de empresas que disputam a oferta desses serviços aos municípios. Conforme exposto na caracterização geral das empresas e no Quadro 4, os pacotes vendidos variam em abrangência e propósito, assim como variam os gastos proporcionais desses municípios em relação a sua manutenção (Tabelas $1 \mathrm{a}$ 3), isso em um contexto de carência de recursos para investimentos e manutenção de aspectos básicos das redes públicas contratantes.

Além de pôr em risco diferentes características do direito à educação, a crescente disseminação dos SPEs nos municípios significa, na prática, o desvio de recursos públicos originalmente destinados à população em geral para a formação de lucro de grandes corporaçóes econômicas. Ou seja, coloca a política educacional em contraposição aos seus objetivos constitucionais ao produzir mais desigualdade e exclusão.

\section{Notas}

1. Este artigo decorre de pesquisa interinstitucional entre o Grupo de Estudos e Pesquisas em Políticas Educacionais (Greppe) e a Ação Educativa denominada Sistemas de Ensino Privados na Educação Pública Brasileira: Consequências da Mercantilização para o Direito à Educação, financiada pela Open Society Foundation.

2. De acordo com o Relatório de Desenvolvimento Humano de 2014 do Programa das Naçôes Unidas para o Desenvolvimento (PNUD), o Índice de Desenvolvimento Humano Municipal (IDHM) é calculado pela média geométrica dos índices de longevidade (expectativa de vida média ao nascer), educação (escolaridade da população adulta e fluxo escolar da população jovem) e renda (renda per capita). As faixas de desenvolvimento humano são fixas: muito baixo desenvolvimento humano, menor que 0,499; baixo, menor que 0,5; médio, entre 0,6 e 0,699; alto, entre 0,7 e 0,799; e muito alto, entre 0,8 e 1.0 .

3. Segundo a Lei de Diretrizes e Bases da Educaçáo Nacional (LDB), os recursos de impostos constitucionalmente vinculados para gastos em educação devem obedecer a uma prescrição específica, contida nos artigos 70 e 71 dessa norma. Entre as despesas que podem ser contabilizadas como MDE estão, conforme o artigo 70: uso e manutenção de bens e serviços vinculados ao ensino; aquisição de material didático escolar; e manutenção de programas de transporte escolar (BRASIL, 1996a).

4. Programa do Ministério da Educação que distribui livros didáticos para todas as escolas públicas de educaçáo básica do Brasil.

5. Na sua origem, Name significava Núcleo de Apoio à Municipalização do Ensino. Foi criado em 1999, como parte das atividades da editora do Colégio Oswaldo Cruz (COC). Em 2010, com a venda para o grupo inglês Pearson de parte dos empreendimentos originários do COC (à época compondo o Sistema Educacional Brasileiro - SEB), o núcleo passou a receber a nova designaçáo, mantendo as funções de ser o representante de uma das atividades do grupo Pearson: a venda de sistemas privados para redes públicas. 
6. Em fevereiro de 2015 o grupo Abril deixou de atuar no mercado educacional: a Abril Educaçáo foi vendida para Thunnus Participaçóes, controlada por fundos geridos pela Tarpon Gestora de Recursos. Mais informaçóes em: <http://oglobo.globo.com/economia/abril-educacao-vendida-fundo-de-investimentos-por-13-bilhao-15288026\#ixzz3TukwjeKA>.

\section{Referências}

ABRIL EDUCAÇÃO. Dados societários. Disponível em: <http://ri.abrileducacao.com.br/ ptbr/companhia/Paginas/mercado.aspx>. Acesso em: 28 nov. 2014.

ADRIÃO, T. et al. A atuação de grupos empresariais em educação e sua inserção em redes públicas de ensino: reflexôes iniciais. Políticas e gestão da educação: desafios em tempos de mudanças. São Paulo: Autores Associados, 2013. p. 267-283.

- Sistemas de ensino privado na educação pública brasileira: consequências da mercantilização para direito à educação. 2015. 113 p. Disponível em: <http://www. campanaderechoeducacion.org/privatizacion/wp-apyus/wp-content/uploads/2016/01/ Peri-Sistemas-de-Ensino-Privado-na-Educa\%C3\%A7\%C3\%A3o-P\%C3\%BAblicaBrasileira-ok.pdf>. Acesso em: 2 fev. 2016.

Uma modalidade peculiar de privatização da educação pública: a aquisição de "sistemas de ensino" por municípios paulistas. Educação \& Sociedade [online], v. 30, n. 108, p. 799-818, 2009.

BASSI, M.E. Financiamento da educação infantil em seis capitais brasileiras. Cadernos de Pesquisa, Sáo Paulo, v. 41, p. 116-141, 2011.

BERTAGNA, R.H.; BORGHI, R. Possíveis relaçóes entre avaliação e sistemas apostilados privados em escolas públicas. Educaçâo: Teoria e Prática [online], Rio Claro, v. 21 , p. $1-15,2011$.

BORGHI, R. Municipalização do ensino fundamental e valorização docente. Educação Unisinos, v. 11, p. 163-173, 2007.

BRASIL. Constituição da República Federativa do Brasil. Brasília: Senado Federal/Centro Gráfico, 1988.

Instituto Nacional de Estudos e Pesquisas Anísio Teixeira (Inep). Censo escolar 2013. Resumo técnico. Brasília: Inep, 2014.

Lei no 9.394 de 1996. Estabelece as diretrizes e bases da educação nacional. Brasília, 1996a.

DALE, R. A promoção do mercado educacional e a polarização da educação. Educação, Sociedade e Culturas, Portugal, n. 12, p. 109-139, 1994.

HILL, D. O neoliberalismo global, a resistência e a deformação da educação. Currículo sem Fronteiras, v. 3, n. 2, p. 24-59, jul./dez. 2003.

MIZUKI, V. Atuação do Ministério Público no processo de expansão de parcerias entre municipios paulistas e empresas educacionais para aquisição de sistemas de ensino. 2013. 
Dissertação (Mestrado em Educação)-Faculdade de Educação, Universidade Estadual de Campinas, Campinas, 2013.

ORGANIZAÇÃO DAS NAÇÓES UNIDAS (ONU). Comitê de Direitos Econômicos, Sociais e Culturais. Observaçâo geral no 13, de 8 de dezembro de 1999, E/C.12/1999/10. 1999.

TOMASEVSKI, K. Human rights obligations: making education available, accessible, acceptable and adaptable. Gothenburg: Swedish International Development Corporation Agency (Sida), 2001. n. 3. (Right to Education).

XIMENES, S.B. Padrão de qualidade do ensino: desafios institucionais e bases para a construção de uma teoria jurídica. 424 f. Tese (Doutorado em Direito do Estado)Universidade de São Paulo, São Paulo, 2014.

Recebido em 11 de dezembro de 2015.

Aprovado em 11 de fevereiro de 2016. 